\title{
Profile of vildagliptin in type 2 diabetes: efficacy, safety, and patient acceptability
}

This article was published in the following Dove Press journal:

Therapeutics and Clinical Risk Management

23 May 2013

Number of times this article has been viewed

CY Pan'

$X L$ Wang $^{2}$

'Chinese PLA General Hospital, Beijing, People's Republic of China; ${ }^{2}$ Medical Affairs Department, Beijing Novartis Pharma Co, Ltd, Beijing,

People's Republic of China
Correspondence: CY Pan

Chinese PLA General Hospital, No.28

Fuxing Street, Beijing, 100853, People's

Republic of China

Email panchy30I@yahoo.com.cn

\begin{abstract}
Vildagliptin is a selective and potent dipeptidyl peptidase-4 inhibitor that improves glycemic control by inhibiting the degradation of both endogenous glucagon-like peptide- 1 and glucose-dependent insulinotropic peptide. This article is a comprehensive review of the safety and efficacy of vildagliptin in patients with type 2 diabetes. Clinical evidence has proven that it effectively decreases hemoglobin $\mathrm{A}_{1 \mathrm{c}}$ with a low risk of hypoglycemia and is weight neutral. The addition of vildagliptin to metformin improves glucose control and significantly reduces gastrointestinal adverse events, particularly in patients inadequately controlled with metformin monotherapy. Its long-term advantages include preservation of $\beta$-cell function, reduction in total cholesterol, decrease in fasting lipolysis in adipose tissue, and triglyceride storage in non-fat tissues. Vildagliptin is well tolerated with a low incidence of AEs, and it does not increase the risk of cardiovascular/cerebrovascular (CCV) events. It can be taken before or after meals, and has little drug interaction, thus it will be well accepted.
\end{abstract}

Keywords: dipeptidyl peptidase-4, incretin hormones, vildagliptin, efficacy, safety, patient acceptability

\section{Introduction}

The prevalence of type 2 diabetes mellitus (T2DM) among adults aged 20-79 years in 2010 was approximately 285 million worldwide. It is estimated that this figure will increase to 430 million by the year $2030 .^{1}$ Many antidiabetic agents are available, including sulfonylureas (SUs), metformin, $\alpha$-glycosidase inhibitors, thiazolidinediones (TZDs), prandial glucose regulators, insulin, and so on.

Recently, a new therapeutic approach for the treatment of type 2 diabetes that targets the incretin hormones has been developed. These peptide hormones, glucagon-like peptide 1 (GLP-1) and glucose-dependent insulinotropic peptide (GIP), are released from the intestine after a meal and stimulate insulin secretion in a glucose-dependent fashion. ${ }^{2}$ However, their action is limited by rapid inactivation by the enzyme dipeptidyl peptidase (DPP)-4. In addition, patients with T2DM usually do not respond well to GIP and GLP-1.3,4 Inhibition of DPP-4 will increase active incretins; therefore, DPP-4 has become a target in diabetes control. ${ }^{5-7}$ To date, several DPP-4 inhibitors are available, including sitagliptin, vildagliptin, saxagliptin, and linagliptin. Their pharmacokinetics/pharmacodynamics, efficacy, safety, and tolerability have been assessed in numerous clinical studies. ${ }^{8}$

Recently, the American Diabetes Association and the European Association for the Study of Diabetes published a joint position statement on the management of hyperglycemia in type 2 diabetes. $^{9}$ 
Key points of this statement include:

- Glycemic targets and glucose-lowering therapies must be individualized.

- Diet, exercise, and education remain the foundation for any type 2 diabetes treatment program.

- Unless there are prevalent contraindications, metformin is the optimal first-line drug.

- After metformin, there are limited data to guide us. Combination therapy with additional 1-2 oral or injectable agents is reasonable, aiming to minimize side effects where possible.

- Ultimately, many patients may require insulin therapy alone or in combination with other agents to maintain glucose control.

- All treatment decisions, where possible, should be made in conjunction with the patient, focusing on his/her preferences, needs, and values.

According to this position statement, in most patients, it is important to begin with lifestyle changes; metformin monotherapy is added at, or soon after, diagnosis (unless there are explicit contraindications). If the hemoglobin $\mathrm{A}_{1 \mathrm{c}}$ $\left(\mathrm{HbA}_{1 \mathrm{c}}\right)$ target is not achieved after about 3 months, consider one of the five treatment options combined with metformin: a SU, TZD, DPP-4 inhibitor, GLP-1 receptor agonist, or basal insulin. Some studies have shown advantages of adding a third noninsulin agent to a two-drug combination that is not yet or no longer achieving the glycemic target. If combination therapy that includes basal insulin has failed to achieve the $\mathrm{HbA}_{1 \mathrm{c}}$ target after 3-6 months, proceed to a more complex insulin strategy, usually in combination with one or two noninsulin agents. In patients intolerant of, or with contraindications for, metformin, select initial drugs from other classes (such as SUs/glinide, pioglitazone, or a DPP-4 inhibitor; in occasional cases where weight loss is seen as an essential aspect of therapy, initial treatment with a GLP-1 receptor agonist might be helpful), and proceed accordingly.

Vildagliptin is a selective and potent DPP-4 inhibitor that inhibits rapid degradation of endogenous GLP-1 and GIP, and increases $\alpha$ - and $\beta$-cell responsiveness to glucose, thereby improving glycemic control in T2DM. ${ }^{10}$ Having a strong binding ability to DPP-4 and a long half-life, vildagliptin is more potent than other DPP-4 inhibitors such as sitagliptin in suppressing glucagon, and causes less glycemic variation. $^{8}$

This paper provides the efficacy, safety, and acceptability of vildagliptin in treating patients with type 2 diabetes.

\section{Short-term efficacy}

It is well established that hyperglycemia, expressed as elevated $\mathrm{HbA}_{1 \mathrm{c}}$, is associated with the risk of microvascular and macrovascular complications. ${ }^{11}$ Reduced rates of microvascular complications in well controlled type 2 diabetic patients were proven by prospective randomized trials. ${ }^{12,13}$ Thus the American Diabetes Association's “Standards of Medical Care in Diabetes" recommends lowering $\mathrm{HbA}_{1 \mathrm{c}}$ to $7.0 \%$ in most patients. ${ }^{14}$ Noninsulin agents differ in potency and effective dosages, with a varied expected $\mathrm{HbA}_{1 \mathrm{c}}$ improvement of $0.5 \%$ to $1.5 \% .{ }^{15}$ However, some patients failed to reach their $\mathrm{HbA}_{1 \mathrm{c}}$ target due to hypoglycemia. In China, insulin secretagogues are the first choice of oral antidiabetic drugs (OADs) (70.2\%), which may account for the high incidence of hypoglycemia (odds ratio $1.76,95 \%$ CI 1.20 to 2.57 ) and poor glycemic control. ${ }^{16}$

DPP-4 inhibitors were said to have an intermediate glucose-lowering effect. ${ }^{17}$ A systematic review of numerous clinical trials had profiled the efficacy and safety of incretinbased therapy. Trials were included in that study if they: (1) were randomized controlled trials of $>12$ weeks' duration; (2) had $>10$ patients with type 2 diabetes per treatment arm; (3) reported changes in hemoglobin $\mathrm{HbA}_{1 \mathrm{c}}$ as the primary endpoint; and (4) studied the effects of adding a single drug (not multiple therapies) in a representative population. That study showed that vildagliptin (50 mg once a day (qd) or twice a day (bid)) is able to reduce $\mathrm{HbA}_{1 \mathrm{c}}$ by $0.98 \%(-1.46 \%$ to $-0.52 \%$ ) after adjusting for differences in baseline $\mathrm{HbA}_{1 \mathrm{c}}{ }^{18}$ Plenty of evidence has supported that vildagliptin consistently and effectively improves glucose control in patients with mild to moderate hyperglycemia as a monotherapy or as an addition to other antidiabetic agents.

\section{Monotherapy}

The efficacy of vildagliptin has been confirmed in a number of controlled trials. ${ }^{19-29}$ Most trials were designed to examine the noninferiority of vildagliptin to the comparator. ${ }^{26-29}$ However, the comparison with other active OADs not only validated its efficacy, but also revealed that it is weight-neutral and has low risk of hypoglycemia.

In a 2-year study of 546 patients, Foley and Sreenan ${ }^{26}$ compared vildagliptin (50 mg bid) with a SU (gliclazide up to $320 \mathrm{mg} /$ day). Similar reductions in $\mathrm{HbA}_{1 \mathrm{c}}$ were found $(-0.5 \%$ versus $-0.6 \%)$, but vildagliptin was weight-neutral and posed little risk of hypoglycemia to patients.

Schweizer et $\mathrm{al}^{29}$ reported a study, in which 780 patients (mean baseline $\mathrm{HbA}_{1 \mathrm{c}}, 8.7 \%$ ) were randomized to accept vildagliptin ( $50 \mathrm{mg}$ bid) or metformin ( $2 \mathrm{~g}$ daily). After 2 years 
of treatment, a significant $\mathrm{HbA}_{1 \mathrm{c}}$ reduction was noticed both in the vildagliptin $(-1.0 \%)$ and metformin $(-1.4 \%)$ groups. However, the metformin group had a twofold higher incidence of gastrointestinal adverse events (AEs).

In another 24-week randomized trial of 786 patients (baseline $\mathrm{HbA}_{1 \mathrm{c}} 8.7 \%$ ), vildagliptin (50 mg bid) was compared to rosiglitazone ( $8 \mathrm{mg} \mathrm{qd})$. Vildagliptin was noninferior to rosiglitazone in reducing $\mathrm{HbA}_{1 \mathrm{c}}(-1.1 \%$ versus $-1.3 \%) .{ }^{28}$ It is worth noting that vildagliptin induced a weight loss of $0.3 \mathrm{~kg}$, whereas rosiglitazone caused a weight gain of $1.6 \mathrm{~kg}(P<0.001)$. In addition, patients treated with vildagliptin had a lower risk of peripheral edema and a better lipid profile.

We had conducted a head-to-head study in which 661 Chinese patients $\left(\mathrm{HbA}_{1 \mathrm{c}} 7.5 \%-11.0 \%\right.$, mean $\left.8.6 \%\right)$ were randomized to vildagliptin $50 \mathrm{mg}$ bid $(\mathrm{n}=441)$ or acarbose up to $100 \mathrm{mg}$ three times a day $(\mathrm{n}=220)$ for 24 weeks. ${ }^{27}$ The adjusted mean $\mathrm{HbA}_{1 \mathrm{c}}$ change (from baseline to the end-point) was $-1.4 \%$ and $-1.3 \%$ in the vildagliptin group and acarbose group, respectively, meeting the statistical criterion for noninferiority. Body weight did not change in the vildagliptin group, but it did decrease in the acarbose group.

According to a pooled analysis of data from five clinical trials with 1569 patients, 24 weeks of vildagliptin monotherapy induced a mean change in $\mathrm{HbA}_{1 \mathrm{c}}$ of $-1.0 \%$. According to baseline $\mathrm{HbA}_{1 \mathrm{c}} 8.0 \%, 8.0 \%-9.0 \%, 9.0 \%-10.0 \%$ and $10.0 \%, \mathrm{HbA}_{1 \mathrm{c}}$ decreased $0.6 \%, 0.9 \%, 1.6 \%$, and $1.9 \%$ from baseline respectively. ${ }^{30}$ Similarly, $\mathrm{HbA}_{1 \mathrm{c}}$ reduction was more substantial in the more obese patients. In addition, the response to vildagliptin in older patients was similar to younger ones $(-1.2 \%$ versus $-1.0 \%$, respectively, $P=0.092)$. Moreover, the rate of hypoglycemia was low $(0.8 \%)$.

\section{Combination therapy}

Vildagliptin has been assessed in randomized, doubleblind trials as an add-on therapy to metformin, SU, thiazolidinedione, and insulin treatment.

\section{Vildagliptin as an add-on therapy to metformin}

Vildagliptin can work well with metformin. First, vildagliptin improves islet function by increasing the sensitivity of the $\alpha$ - and $\beta$-cells to glucose, ${ }^{25}$ whereas metformin reduces hepatic glucose and improves insulin resistance. ${ }^{31}$ It is rational to combine an agent primarily targeting insulin sensitivity within the pancreas, like vildagliptin, with an agent primarily targeting insulin resistance, like metformin. Metformin is the optimal first-line drug for patients who failed to achieve their target with lifestyle interventions alone. Secondly, metformin also has a positive effect on promoting endogenous intact GLP-1 levels, ${ }^{32}$ presumably by increasing its synthesis but not inhibiting degradation. ${ }^{33,34}$ Subjects taking vildagliptin with metformin caused about two times elevations in fasting plasma GLP-1 than in taking vildagliptin alone, ${ }^{35,36}$ The following section presents some clinical evidence supporting vildagliptin as an add-on therapy to metformin in patients inadequately controlled with metformin monotherapy.

\section{Vildagliptin versus placebo as an add-on therapy to metformin}

A 24-week study was performed in 544 patients who failed to achieve glucose control $\left(\mathrm{HbA}_{1 \mathrm{c}} 7.5 \%-11 \%\right)$ with metformin ( $\geq 1500 \mathrm{mg} /$ day) alone. The patients were randomized to receive an addition of vildagliptin $50 \mathrm{mg} /$ day $(\mathrm{n}=177)$, or an addition of vildagliptin $100 \mathrm{mg}$ /day $(\mathrm{n}=185)$, or metformin/placebo $(\mathrm{n}=182)$. Compared with the metformin/placebo arm, a change in $\mathrm{HbA}_{1 \mathrm{c}}$ from baseline to the study endpoint was $-0.7 \%$ and $-1.1 \%$ in patients receiving $50 \mathrm{mg}$ or $100 \mathrm{mg}$ of vildagliptin daily, respectively; likewise, the between-treatment difference (vildagliptin - placebo) in fasting plasma glucose was $-0.8 \mathrm{mmol} / \mathrm{L}$ and $-1.7 \mathrm{mmol} / \mathrm{L}$ in the vildagliptin $50 \mathrm{mg}$ or $100 \mathrm{mg}$ groups, respectively. Body weight did not change significantly from baseline after 24 weeks of treatment with vildagliptin $50 \mathrm{mg} /$ day $(-0.4 \mathrm{~kg})$ or vildagliptin $100 \mathrm{mg} /$ day $(+0.2 \mathrm{~kg})$, while in patients receiving metformin/placebo, body weight decreased by $-1.0 \mathrm{~kg}(P<0.001)$. There were no significant differences between the three groups in terms of AEs, except for the experience of gastrointestinal AEs. Gastrointestinal AEs were reported by $9.6 \%, 14.8 \%$, and $18.2 \%$ of patients receiving $50 \mathrm{mg}$ vildagliptin daily, $100 \mathrm{mg}$ vildagliptin daily, or placebo, respectively $(P=0.022$ versus placebo). One patient in each treatment group experienced one mild hypoglycemic event. ${ }^{37}$

In another randomized control trial, T2DM patients inadequately controlled with metformin $1500 \mathrm{mg} /$ day $\left(7 \% \leq \mathrm{HbA}_{1 \mathrm{c}} \leq 7 \%\right.$ to $11 \%$, mean $8.14 \%$ to $\left.8.16 \%\right)$ were assigned to the $1500 \mathrm{mg}$ of metformin and $50 \mathrm{mg}$ of vildagliptin bid group $(\mathrm{n}=132)$, and the metformin $2500 \mathrm{mg}$ group $(\mathrm{n}=125)$. After 24 weeks of treatment, $\mathrm{HbA}_{1 \mathrm{c}}$ decreased by $1.25 \%$ in the vildagliptin/metformin group and $0.9 \%$ in the metformin group $(P<0.0001)$. AEs and gastrointestinal AEs were significantly less in the vildagliptin/ metformin group $(3.8 \%, 3.0 \%)$ than those in metformin arm $(10.7 \%, 9.2 \%){ }^{38}$ 
Vildagliptin versus SUs as an add-on therapy to metformin

A total of 3118 T2DM patients who failed to achieve their $\mathrm{HbA}_{1 \mathrm{c}}$ target $\left(\mathrm{HbA}_{1 \mathrm{c}} 6.5 \%\right.$ to $8.5 \%$, mean $\left.7.3 \%\right)$ after metformin monotherapy were randomized into either metformin/vildagliptin $(\mathrm{n}=1562)$ or metformin/glimepiride treatment groups $(n=1556)$. The dosage of vildagliptin was $50 \mathrm{mg}$ bid, while up to $6 \mathrm{mg}$ /day of glimepiride was prescribed in the control arm. After 2 years of treatment, the adjusted mean change in $\mathrm{HbA}_{1 \mathrm{c}}$ was similar between the two groups: $-0.1 \%(0.0 \%)$ and $-0.1 \%(0.0 \%)$, respectively. Although the initial response rate was similar between the two groups, more patients with vildagliptin reached their target $\mathrm{HbA}_{1 \mathrm{c}}$ without hypoglycemia (36.0\% versus $28.8 \%, P=0.004)$. Hypoglycemic events that occurred in the metformin/glimepiride group were 14-fold as high as those in metformin/vildagliptin group (838 versus 59). Body weight change was $-0.3 \mathrm{~kg}$ in the vildagliptin group versus $1.2 \mathrm{~kg}$ in glimepiride group $(P<0.001)$. Both treatments were well tolerated and displayed similar safety profiles. ${ }^{39}$

\section{Vildagliptin versus TZDs as an add-on therapy to metformin}

A 52-week, randomized, active-controlled study compared vildagliptin (50 $\mathrm{mg}$ bid, $\mathrm{n}=295)$ with pioglitazone $(30 \mathrm{mg}$ $\mathrm{qd}, \mathrm{n}=281)$ in patients inadequately controlled $\left(\mathrm{HbA}_{1 \mathrm{c}}\right.$ $7.5 \%$ to $11 \%$ ) with a stable dose of metformin ( $\geq 1500 \mathrm{mg}$ ). Vildagliptin was found to be noninferior to pioglitazone in lowering $\mathrm{HbA}_{1 \mathrm{c}}$ throughout the trial period. In addition, vildagliptin did not significantly increase body weight $(+0.2 \mathrm{~kg})$, whereas pioglitazone induced a weight gain of $2.6 \mathrm{~kg}$. Hypoglycemia occurred rarely in both groups. There were no significant differences in the overall $\mathrm{AE}$ rates between the two groups; however, serious AEs occurred more frequently in the pioglitazone group. ${ }^{40,41}$

Another 12-week randomized open-label study compared vildagliptin (100 mg, $\mathrm{n}=1653$ ) with TZD (agent and dose at the investigators' discretion, $\mathrm{n}=825$ ) as an add-on therapy in patients inadequately controlled $\left(\mathrm{HbA}_{1 \mathrm{c}} 7 \%\right.$ to $10 \%$ ) on a stable dose of metformin ( $\geq 1000 \mathrm{mg} /$ day). The mean change in $\mathrm{HbA}_{1 \mathrm{c}}$ from baseline to the study endpoint was $-0.68 \%$ in the vildagliptin group and $-0.57 \%$ in the TZD group, meeting the noninferiority criteria. Body weight increased in the TZD group $(0.33 \mathrm{~kg})$ and decreased in the vildagliptin group $(-0.58 \mathrm{~kg}, P<0.001)$. Adverse events occurred in similar proportions of patients in both groups (vildagliptin 39.5\% and TZD 36.3\%), and hypoglycemia was rare. ${ }^{42}$

\section{Vildagliptin as an add-on therapy to SU}

A 24-week, multicenter, randomized, double-blinded, placebo-controlled study assessed the effect of vildagliptin (50 mg qd or bid) versus placebo added to glimepiride (4 mg qd) in 515 T2DM patients. Compared with placebo, a change in $\mathrm{HbA}_{1 \mathrm{c}}$ from baseline to the study's endpoint was $-0.6 \%$ in patients receiving vildagliptin $50 \mathrm{mg} /$ day, and $-0.7 \%$ in those receiving vildagliptin $100 \mathrm{mg} /$ day. Greater efficacy was seen in patients $\geq 65$ years of age $(-0.7 \%$ for $50 \mathrm{mg} /$ day, $-0.8 \%$ for $100 \mathrm{mg} /$ day), and in patients with $\mathrm{HbA}_{1 \mathrm{c}}$ levels $>9.0 \%$ $(-1.0 \%$ for $50 \mathrm{mg} /$ day, $-0.9 \%$ for $100 \mathrm{mg} /$ day $)$. The incidences of AEs $(67.1 \%, 66.3 \%$, and $64.2 \%)$ and serious AEs $(2.9 \%, 2.4 \%$, and $5.1 \%)$ were similar in the three groups. The incidence was low but slightly higher in the vildagliptin $100 \mathrm{mg}$ group (3.6\%) than in both the vildagliptin $50 \mathrm{mg}$ group (1.2\%) and the control arm $(0.6 \%)$. The results showed that in T2DM patients inadequately controlled with SU monotherapy, the addition of vildagliptin to glimepiride improves glycemic control and is well tolerated. The addition of vildagliptin $50 \mathrm{mg} /$ day to a SU may be a particularly attractive therapy in elderly patients. ${ }^{43}$

\section{Vildagliptin as an add-on therapy to other antidiabetic drugs}

Vildagliptin had been added to other antidiabetic drugs, such as pioglitazone, ${ }^{44}$ and insulin in patients inadequately controlled with monotherapy. ${ }^{45-47}$ The reduction in $\mathrm{HbA}_{1 \mathrm{c}}$ varied from $0.5 \%$ to $1.0 \%$ with different dosages of vildagliptin. Vildagliptin posed a low risk of hypoglycemia when combined with pioglitazone or insulin, ${ }^{44,46,47}$ and the weight gain was more apparent in the vildagliptin/insulin group. ${ }^{46}$

\section{Long-term benefit of vildagliptin}

Vildagliptin showed long-term benefit for type 2 diabetes by preserving $\beta$-cell function and normalizing the lipid profile.

\section{Effect of vildagliptin on $\beta$-cell function}

In animal studies, vildagliptin was observed to preserve $\beta$-cell function by increasing $\beta$-cell mass, ${ }^{48}$ stimulating $\beta$-cell replication, ${ }^{49}$ or reducing apoptosis. ${ }^{50}$ The $\beta$-cell mass increase may partly be attributed to the developmental regulation and suppression of oxidation and endoplasmic reticulum stress. ${ }^{51}$

Studies of vildagliptin in patients with type 2 diabetes demonstrated improvements in meal-test derived markers of $\beta$-cell function. ${ }^{21,25,28,37,44,52-54}$ The homeostatic model assessment- $\beta$ was increased while the proinsulin to insulin 
ratio was decreased by vildagliptin..$^{53}$ Insulin secretion [defined as the ratio of the incremental area under the curve ( $\triangle \mathrm{AUC}$ ) for C-peptide to the $\triangle \mathrm{AUC}$ for glucose during standard meal tests] increased by $>30 \%$ from 12 weeks throughout 1 year of treatment. ${ }^{54}$ Some trials calculated the insulin secretory rate (ISR) by deconvolution of C-peptide levels, and used the $\triangle \mathrm{AUC}$ for ISR/ $\triangle \mathrm{AUC}$ for glucose (ISR/G) as a $\beta$-cell function index. This index was consistently found to be increased in patients receiving vildagliptin in monotherapy, ${ }^{53}$ or as an add-on to glimepiride, ${ }^{43}$ a thiazolidinedione,${ }^{44}$ or metformin. ${ }^{55}$ Further, given a single dose of vildagliptin before the evening meal, insulin secretion relative to glucose (ISR/G) increased significantly overnight. ${ }^{52}$ There is evidence that has shown that vildagliptin increased $\beta$-cell function (assessed as ISR/G) in different populations, including those with IFG,${ }^{57}$ impaired glucose tolerance, ${ }^{56}$ or T2DM, and mild hyperglycemia. ${ }^{20}$ Clinical trials have also demonstrated that the insulin demand was brought down by adding vildagliptin, which achieved a negative caloric balance. ${ }^{45,46}$

\section{Effect of vildagliptin on plasma lipids}

The lipid profile is an important determinant of cardiovascular risk in type 2 diabetes. ${ }^{58,59}$ It is conceivable that glucoselowering agents have a positive impact on the lipid profile due to the close relationship between glucose and lipid metabolism. A meta-analysis including five trials showed that vildagliptin significantly reduced the total cholesterol level (the difference in means, $-0.42 \mathrm{mmol} / \mathrm{L}, 95 \%$ CI -0.59 to $-0.25 \mathrm{mmol} / \mathrm{L}, P<0.001),{ }^{60}$ but the results of other lipid parameters are inconsistent across trials (see Table 1). ${ }^{19,28,29,41,61}$

Some researchers have addressed the underlying mechanism of the change in lipid profiles after vildagliptin therapy. In animal studies, both GLP-1 and GIP inhibit lipolysis, indicating that the effect of vildagliptin is incretin hormone-mediated. In humans, vildagliptin was found to reduce fasting lipolysis, and increase postprandial lipolysis in adipose tissue as well as postprandial fat oxidation in muscle. These results indicated that the fat accumulated in adipocytes during fasting, and became mobilized and burned in muscle after meals. ${ }^{6}$ Further, decreasing fasting lipolysis over 6 weeks is predicted to decrease stored triglycerides in nonfat tissues. ${ }^{63}$ In summary, in addition to preserving $\beta$-cell function, vildagliptin improves insulin resistance by reducing glucose-toxicity, decreasing fasting lipolysis in fat cells, and reducing stored triglycerides in muscle, the liver, and pancreas.

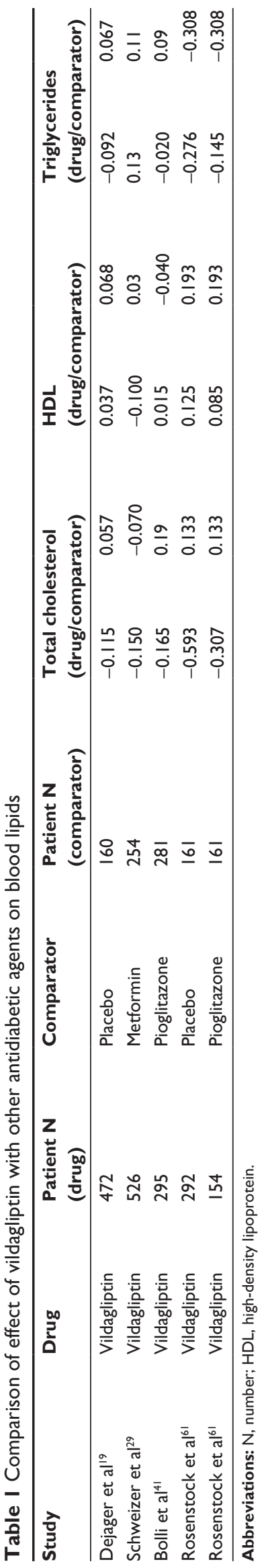

Therapeutics and Clinical Risk Management 2013:9 


\section{Effects of vildagliptin on surrogate markers of atherosclerosis}

In an animal study, 17-week-old ApoE (-/-) mice fed an atherogenic diet were administered a DPP-4 inhibitor, vildagliptin analogue (PKF275-055 [PKF], $100 \mu \mathrm{g} / \mathrm{kg} /$ day), over a period of 4 weeks. Aortic atherosclerosis and oxidized low-density lipoprotein-induced foam cell formation were determined. PKF increased the plasma levels of active glucagon-like peptide- 1 by 3.5 -fold, increased the total glucose-dependent insulinotropic polypeptide levels by twofold, reduced body weight by $13 \%$, and reduced plasma cholesterol levels by $30 \%$. Compared with drinking water controls, PKF significantly suppressed total aortic atherosclerotic lesions, atheromatous plaques in the aortic root, and macrophage accumulation in the aortic wall by $30 \%$ to $40 \%(P<0.001)$. Foam cell formation was suppressed by $40 \%{ }^{64}$

In another animal study, 14 pigs were randomized to receive either a DPP-4 inhibitor (vildagliptin; $50 \mathrm{mg}$ ) or normal saline intravenously prior to a 90 -minute left anterior descending artery occlusion, followed by a 120-minute reperfusion period. The hemodynamic, cardiac, electrophysiological, and arrhythmic parameters, as well as the infarct size were determined before and during interventional radiology. During interventional radiology, the DPP-4 inhibitor stabilized the cardiac electrophysiology by preventing the event-related potential shortening, decreasing the number of preventricular contractions, increasing the ventricular fibrillation threshold, and decreasing the infarct size. ${ }^{65}$

In a 12-week animal study, male Wistar rats were fed with either a normal diet or a high-fat diet ( $\mathrm{n}=24$ in each group). Rats in each group were divided into three subgroups to receive the vehicle, metformin (30 mg/kg, bid), or vildagliptin $(3 \mathrm{mg} / \mathrm{kg}$, qd) for another 21 days. Heart rate variability, cardiac function, and cardiac mitochondrial function were determined and compared among these treatment groups. Rats exposed to a high-fat diet developed increased body weight, visceral fat, plasma insulin, cholesterol, oxidative stress, depressed heart rate variability, and cardiac mitochondrial dysfunction. It was found that vildagliptin was more effective in preventing cardiac sympathovagal imbalance and cardiac dysfunction, as well as cardiac mitochondrial dysfunction, than metformin in rats with insulin resistance induced by a high-fat diet. ${ }^{66}$

Matsui et al ${ }^{67}$ investigated whether vildagliptin inhibits vascular damage in the thoracic aorta of Otsuka LongEvans Tokushima Fatty rats (OLETF rats), an animal model of type 2 diabetes with obesity, by blocking the advanced glycation end product-receptor for advanced glycation end product (AGE-RAGE) axis. OLETF and control Long-Evans Tokushima Otsuka (LETO) rats at 22 weeks old were given a vehicle or $3 \mathrm{mg} / \mathrm{kg}$ of vildagliptin for another 12 weeks. Vildagliptin treatment significantly inhibited levels of AGE, RAGE, mRNA, protein, an oxidative stress marker, 8-hydroxydeoxyguanosine, two membrane components of nicotinamide adenine dinucleotide phosphate oxidase, p22, and gp91phox mRNAs, as well as phospho-NF-кB p65. Vildagliptin also significantly reduced both mRNA and protein levels of monocyte chemoattractant protein-1, vascular cell adhesion molecule-1, and plasminogen activator inhibitor-1. All these data suggest that vildagliptin could play a protective role against vascular injury in diabetes partly by attenuating the deleterious effects of the AGE-RAGEoxidative stress axis.

\section{Safety}

The most frequent AEs of vildagliptin were gastrointestinal AEs, hypoglycemia, headache, nasopharyngitis, influenza, cough, edema, and dizziness. Although the absolute occurrence was low, the incidence of AEs while taking vildagliptin varied in different trials when compared with placebo. ${ }^{20,21,68-70}$ However, the incidence of gastrointestinal AEs, as well as the total AEs were significantly lower with vildagliptin compared with metformin, ${ }^{55,71}$ and $\alpha$-glycosidase inhibitors. ${ }^{27,72}$ Dizziness and upper respiratory infections were more common in the vildagliptin group compared with TZDs. ${ }^{28,61}$ A meta-analysis summarized the AEs of vildagliptin. ${ }^{73}$ In that analysis, vildagliptin was not related to an increase in overall risk for any AEs when compared with placebo (relative risk (RR), 0.97 ; $95 \%$ CI 0.94 to 0.99 ); the incidence of hypoglycemia was low with vildagliptin, and the risk was similar to the comparators (RR $0.85,95 \%$ CI 0.49 to 1.47 ). The use of vildagliptin did not pose any additional risks of infection for nasopharyngitis (RR 1.03, 95\% CI 0.94 to 1.13) or for upper respiratory tract infections (RR 1.07, 95\% CI 0.90 to 1.27$)$.

\section{Risk of hypoglycemia}

There is emerging concern about the increased risk of brain dysfunction in patients with repeated episodes of hypoglycemia, which may also lead to dysrhythmias, dizziness, confusion, or infection, which can be especially dangerous in the elderly. ${ }^{74}$ Further, the frequency of both minor and major hypoglycemia was threefold higher in intensively managed patients than the frequency associated with conventional therapy in the ACCORD trial, ${ }^{75}$ indicating a tight control target 
is more likely to cause hypoglycemia events. Accordingly, in at-risk individuals, drug selection should favor agents that do not precipitate such events and, in general, blood glucose targets may need to be moderated. ${ }^{9}$

Clinical evidence has shown that vildagliptin caused fewer hypoglycemic events than insulin secretagogues, no matter of whether it was used as a monotherapy or combined with other agents. Twenty-nine studies with almost 15,000 participants showed that the risk of hypoglycemia occurs at the placebo level for all gliptins in the absence of insulin or SU cotherapy. ${ }^{88}$ Moreover, ten trials with over 4700 participants indicated that as part of a combination therapy with an SU or insulin, the risk of hypoglycemia is elevated with sitagliptin and or linagliptin, but vildagliptin and saxagliptin appear to be safer agents to use in this context. ${ }^{76}$ Of course, further studies are needed to clarify these differing hypoglycemia potentials.

The distinctive pharmacological characteristics of vildagliptin could explain its advantage. The mechanism of action of vildagliptin is quite different from that of SUs, which work by closing adenosine triphosphate-sensitive potassium channels on $\beta$-cells and stimulates insulin release. ${ }^{77} \mathrm{SUs}$ increase insulin secretion independent of plasma glucose levels over time, ${ }^{78}$ decrease the sensitivity of the $\alpha$ - and $\beta$-cells to glucose, ${ }^{79}$ and exacerbate islet dysfunction after long-term use. ${ }^{80}$ On the contrary, active endogenous GLP-1 and GIP concentrations are increased two- to threefold by vildagliptin, lowering blood sugar in a glucose-dependent way after a meal, which is anticipated to have a low risk of hypoglycemia. Furthermore, vildagliptin not only suppresses inappropriate glucagon secretion in response to glucose or mixed meals, but also enhances $\alpha$-cell responsiveness to the stimulatory effect of hypoglycemia. ${ }^{25}$ When hypoglycemia occurs, glucagon levels were significantly higher in the vildagliptin group than in the placebo group (see Figure 1), ${ }^{25}$ possibly due to the attenuation or abstentions of inhibition of glucagon secretion by GLP-1, and maximized stimulation of glucagon secretion by GIP. ${ }^{81}$ Vildagliptin also extends the surge in GLP-1 and GIP after meals to intermeal and overnight periods, ${ }^{52,82}$ which may protect the body from hypoglycemia (see Figure 2). Taken together, the bifunctional effect on glucagon by vildagliptin can well explain the low risk of hypoglycemia caused by vildagliptin when glycemic control is achieved.

\section{Effect of vildagliptin on body weight}

In overweight or obese patients with type 2 diabetes, successful weight loss can improve glycemic control and reduce concomitant cardiovascular risk factors, such as hypertension and dyslipidemia. ${ }^{83}$ The effect of antidiabetic drugs on weight is considered to be an important issue in the selection of therapy. GLP-1 receptor agonists and metformin were associated with weight loss, whereas insulin, insulin secretagogues (eg, SUs and TZDs) were all associated with weight gain. ${ }^{14}$

Clinical trials have demonstrated that vildagliptin has a neutral effect on weight, which is partly explained by its low risk for hypoglycemia. Hypoglycemia is more common in patients treated with weight-gain insulin or SUs. In addition, the experience of hypoglycemia was often followed by "defensive eating," leading to an excess of caloric intake. ${ }^{12}$

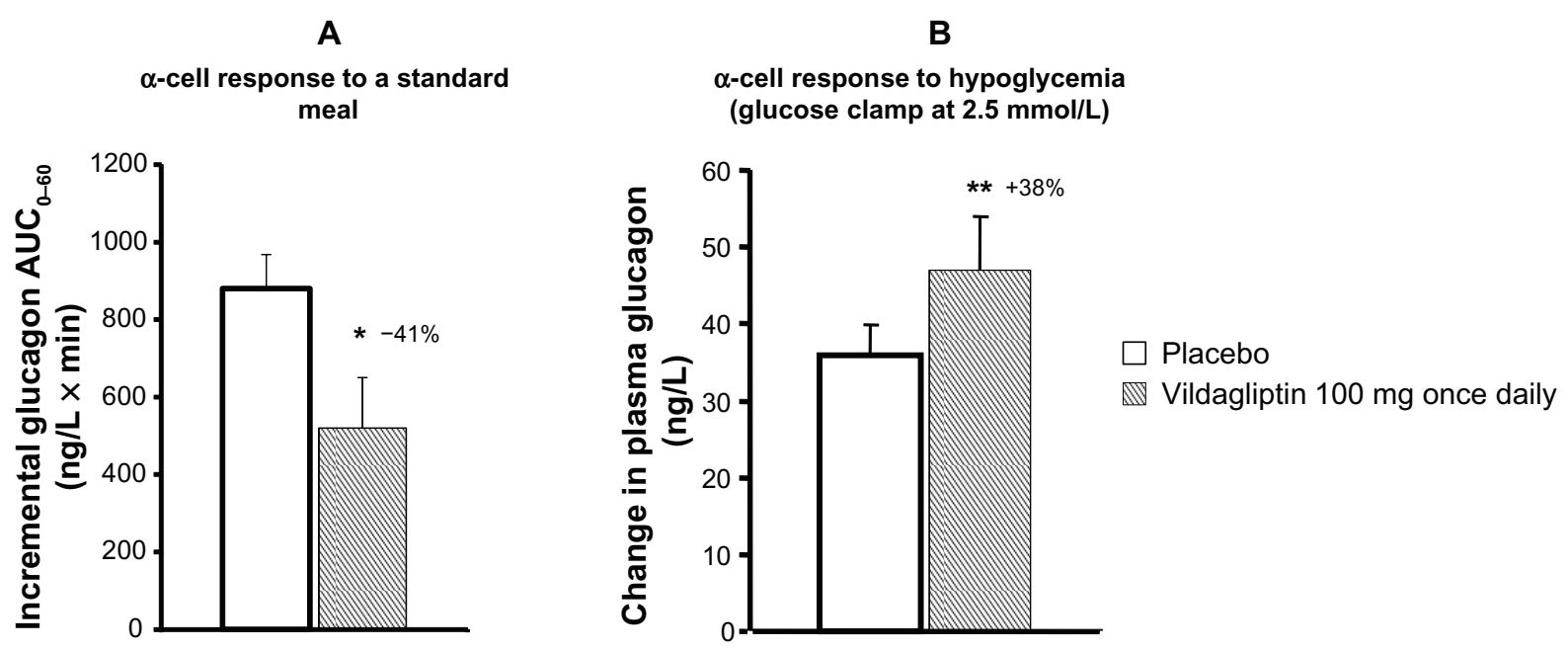

Figure I Effect of vildagliptin on $\alpha$-cell function in hyperglycemia $(\mathbf{A})$ and hypoglycemia (B).

Notes: $* P=0.019 ; * * P=0.039$.

Adapted with permission from Ahrén B, Landin-Olsson M, Jansson PA, Svensson M, Holmes D, Schweizer A. Inhibition of dipeptidyl peptidase-4 reduces glycemia, sustains insulin levels, and reduces glucagon levels in type 2 diabetes. J Clin Endocrinol Metab. 2004;89(5):2078-2084.24 @2009, The Endocrine Society.

Abbreviation: AUC, area under the curve. 
A

A

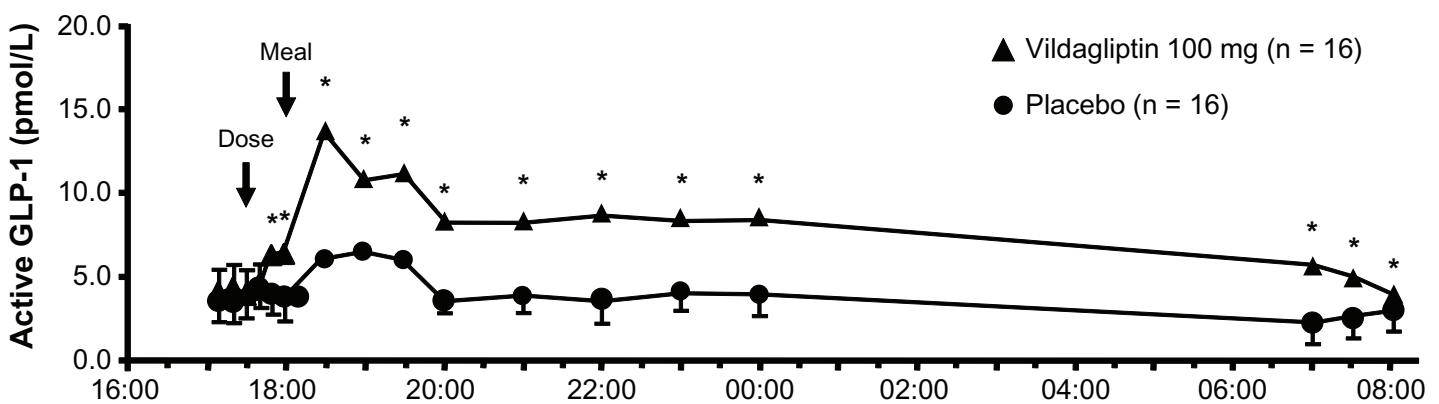

B

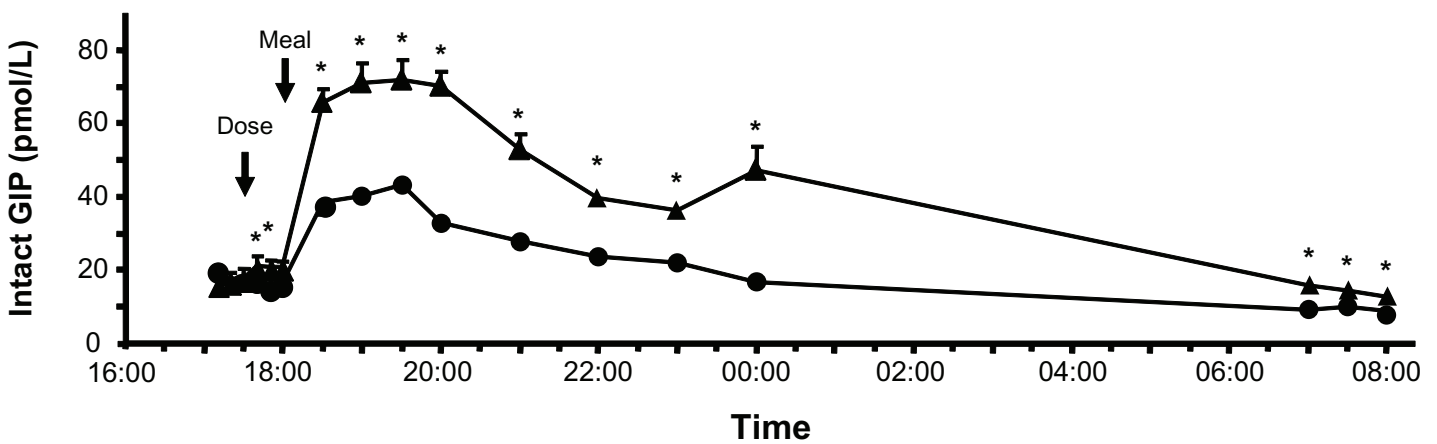

Figure 2 Instant effect of vildagliptin $100 \mathrm{mg} /$ day versus placebo on glucose fluctuations.

Note: $* P<0.05$ or better than placebo. Plasma GLP-I(A), GIP(B) during the meal tolerance test after ingestion of vildagliptin and placebo. Data are the mean \pm SE. Adapted with permission from Balas B, Baig MR, Watson C, et al. The dipeptidyl peptidase IV inhibitor vildagliptin suppresses endogenous glucose production and enhances islet function after single-dose administration in type 2 diabetic patients. J Clin Endocrinol Metab. 2007;92(4): I 249-I255. ${ }^{52}$ (C) 2007, The Endocrine Society.

Abbreviations: GLP-I, glucagon-like peptide-I; GIP, gastric inhibitory polypeptide.

Vildagliptin can prevent defensive eating by decreasing the risk of hypoglycemia.

It has also been found that vildagliptin significantly lowered chylomicron lipid and apolipoprotein levels, suggesting that it may inhibit intestinal fat extraction. ${ }^{63}$ Another trial demonstrated that vildagliptin can increase norepinephrine levels and promote lipolysis through sympathetic stimulation, in conjunction with the postprandial fatty acid mobilization and oxidation. ${ }^{62}$ These new potential roles of vildagliptin may also contribute to its weight-neutral effect.

\section{Cardiovascular and cerebrovascular safety}

Cardiovascular and cerebrovascular (CCV) events are comorbidities of T2DM, and the major cause of death in such settings. ${ }^{84,85}$ To reduce CCV incidence is always the treatment target of type 2 diabetes. Unexpectedly, however, some antidiabetic agents are associated with increased risk of $\mathrm{CV}$ AEs. ${ }^{86,87}$ Thus, the evaluation of CCV risk of therapy is very important. A systematic review pooled studies of patients treated with vildagliptin and analyzed its $\mathrm{CCV}$ safety. ${ }^{88} \mathrm{~A}$ total of 25 Phase III studies of vildagliptin $(\mathrm{n}=7509)$, used either as monotherapy or as part of combination therapy (placebo or comparators, $\mathrm{n}=6061$ ), with durations of 12 weeks to $\geq 2$ years were included. Outcomes included the composite endpoints of acute coronary syndrome, transient ischemic attack (with imaging evidence of infarction), stroke, and $\mathrm{CCV}$ death. Compared with all comparators, the RRs for the composite endpoint were $<1$ for both vildagliptin $50 \mathrm{mg} \mathrm{qd}$ (RR $0.88,95 \%$ CI 0.37 to 2.11) and vildagliptin $50 \mathrm{mg}$ bid (RR $0.84,95 \%$ CI 0.62 to 1.14), which were also consistent across subgroups defined by age, gender, and CV risk status. As a conclusion, vildagliptin did not increase the risk of adjudicated CCV events relative to all comparators in the broad population of type 2 diabetics, including those at increased risk of $\mathrm{CCV}$ events.

\section{Safety of vildagliptin in patients with chronic kidney disease}

In a 24-week study of 515 patients with T2DM and moderate or severe renal impairment (RI), vildagliptin was added to ongoing antidiabetic therapy. After 24 weeks, the betweentreatment difference in the adjusted mean change in $\mathrm{HbA}_{1 \mathrm{c}}$ was $-0.5 \% \pm 0.1 \%(P<0.0001)$ in moderate RI (baseline $\left.\mathrm{HbA}_{1 \mathrm{c}}=7.9 \%\right)$, and $-0.6 \% \pm 0.1 \%(P<0.0001)$ in severe RI (baseline $\mathrm{HbA}_{1 \mathrm{c}}=7.7 \%$ ). In patients with moderate RI, similar proportions of those receiving vildagliptin or placebo experienced any AE ( $68 \%$ versus $73 \%$, respectively), any serious $\mathrm{AE}$ ( $9 \%$ versus $9 \%$, respectively), any $\mathrm{AE}$ leading to discontinuation ( $3 \%$ versus $5 \%$, respectively), or 
death ( $1 \%$ versus $1 \%$, respectively). This was also true for patients with severe RI: AEs (73\% versus 74\%, respectively), serious AEs (19\% versus 21\%, respectively), AEs leading to discontinuation ( $9 \%$ versus $6 \%$, respectively), and death ( $2 \%$ versus $4 \%$, respectively). Vildagliptin added to ongoing antidiabetic therapy had a safety profile similar to placebo. Furthermore, relative to placebo, vildagliptin elicited a satisfactory and clinically significant decrease in $\mathrm{HbA}_{1 \mathrm{c}}$ in patients with moderate or severe RI. ${ }^{89}$

\section{Patients' acceptability}

Diabetes, including T2DM is usually a lifelong (chronic) disease. One study has shown that patients' poor adherence to therapy is a great obstacle in achieving their glycemic control target. ${ }^{90}$ Therefore, the patients' acceptability of antidiabetic agents is as important as their efficacy and safety. Unlike some SUs, meglitinides (which should be given before a meal), and alpha-glucosidase inhibitors (which should be taken just prior to ingesting the first portion of each meal), vildagliptin can be ingested at any time of the day. Unlike insulin, which requires an injection, vildagliptin is an oral glucose-lowering agent. In addition, it has little drug interaction and it can be combined with other OADs. Vildagliptin is currently approved in the European Union for use in combination with metformin and TZD at $50 \mathrm{mg}$ bid, with SU at $50 \mathrm{mg}$ $\mathrm{qd}$, or prepared in a fixed-dose and combined with metformin (50 mg/500 mg, $50 \mathrm{mg} / 850 \mathrm{mg}$, and $50 \mathrm{mg} / 1000 \mathrm{mg}$ ). All of these advantages of vildagliptin promote patients' adherence for long-term treatment.

\section{Conclusion}

Vildagliptin is a potent DPP-4 inhibitor. When used alone or added to other OADs, it effectively improves glycemic control, preserves both the $\alpha$ - and $\beta$-cell function, and reduces lipotoxicity and insulin resistance. This drug is well tolerated and is weight-neutral. It poses a low risk of AEs to patients, including hypoglycemia, as well as CCV events. Vildagliptin can be taken before or after a meal, and has little drug interaction; thus, it will be well accepted.

\section{Disclosure}

The authors report no conflicts of interest in this work.

\section{References}

1. Shaw JE, Sicree RA, Zimmet PZ. Global estimates of the prevalence of diabetes for 2010 and 2030. Diabetes Res Clin Pract. 2010; 87(1):4-14.

2. Holz GG 4th, Kühtreiber WM, Habener JF. Pancreatic beta-cells are rendered glucose-competent by the insulinotropic hormone glucagon-like peptide-1 (7-37). Nature. 1993;361(6410):362-365.
3. Freeman JS. The pathophysiologic role of incretins. J Am Osteopath Assoc. 2007;107 Suppl:S6-S9.

4. Nauck MA, Baller B, Meier JJ. Gastric inhibitory polypeptide and glucagon-like peptide-1 in the pathogenesis of type 2 diabetes. Diabetes. 2004;53 Suppl 3:S190-S196.

5. Ahrén B, Foley JE. The islet enhancer vildagliptin: mechanisms of improved glucose metabolism. Int J Clin Pract Suppl. 2008;159:8-14.

6. Banerjee M, Younis N, Soran H. Vildagliptin in clinical practice: a review of literature. Expert Opin Pharmacother. 2009;10(16):2745-2757.

7. Palalau AI, Tahrani AA, Piya MK, Barnett AH. DPP-4 inhibitors in clinical practice. Postgrad Med. 2009;121(6):70-100.

8. Thornberry NA, Gallwitz B. Mechanism of action of inhibitors of dipeptidyl-peptidase-4 (DPP-4). Best Pract Res Clin Endocrinol Metab. 2009;23(4):479-486.

9. Inzucchi SE, Bergenstal RM, Buse JB, Diamant M, et al; for American Diabetes Association (ADA), European Association for the Study of Diabetes (EASD). Management of hyperglycemia in type 2 diabetes: a patient-centered approach: position statement of the American Diabetes Association (ADA) and the European Association for the Study of Diabetes (EASD). Diabetes Care. 2012;35(6):1364-1379.

10. Keating GM. Vildagliptin: a review of its use in type 2 diabetes mellitus. Drugs. 2010;70(16):2089-2112.

11. Stratton IM, Adler AI, Neil HA, et al. Association of glycaemia with macrovascular and microvascular complications of type 2 diabetes (UKPDS 35): prospective observational study. BMJ. 2000; 321(7258):405-412.

12. Intensive blood-glucose control with sulphonylureas or insulin compared with conventional treatment and risk of complications in patients with type 2 diabetes (UKPDS 33). UK Prospective Diabetes Study (UKPDS) Group. Lancet. 1998;352(9131):837-853.

13. UK Prospective Diabetes Study (UKPDS). VIII. Study design, progress and performance. Diabetologia. 1991;34(12):877-890.

14. American Diabetes Association. Standards of medical care in diabetes 2011. Diabetes Care. 2011;34 Suppl 1:S11-S61.

15. Bennett WL, Maruthur NM, Singh S, et al. Comparative effectiveness and safety of medications for type 2 diabetes: an update including new drugs and 2-drug combinations. Ann Intern Med. 2011;154(9): 602-613.

16. Ji L, LJ, Weng J, et al. China Type 2 Diabetes Treatment Status Survey of Treatment Pattern of Oral Drugs Users (China DiaSTAGE). Berlin: The 48th European Association for the Study of Diabetes; 2012.

17. Peters A. Incretin-based therapies: review of current clinical trial data. Am J Med. 2010;123(Suppl 3):S28-S37.

18. Aroda VR, Henry RR, Han J, Huang W, et al. Efficacy of GLP-1 Receptor Agonists and DPP-4 Inhibitors: Meta-Analysis and Systematic Review. Clin Ther. 2012 Jun;34(6):1247-1258

19. Dejager S, Razac S, Foley JE, Schweizer A. Vildagliptin in drug-naïve patients with type 2 diabetes: a 24-week, double-blind, randomized, placebo-controlled, multiple-dose study. Horm Metab Res. 2007;39(3):218-223.

20. Scherbaum WA, Schweizer A, Mari A, et al. Evidence that vildagliptin attenuates deterioration of glycaemic control during 2-year treatment of patients with type 2 diabetes and mild hyperglycaemia. Diabetes Obes Metab. 2008;10(11):1114-1124

21. Scherbaum WA, Schweizer A, Mari A, et al. Efficacy and tolerability of vildagliptin in drug-naïve patients with type 2 diabetes and mild hyperglycaemia*. Diabetes Obes Metab. 2008;10(8):675-682.

22. Foley JE, Bunck MC, Möller-Goede DL, et al. Beta cell function following 1 year vildagliptin or placebo treatment and after 12 week washout in drug-naive patients with type 2 diabetes and mild hyperglycaemia: a randomised controlled trial. Diabetologia. 2011;54(8):1985-1991.

23. Pi-Sunyer FX, Schweizer A, Mills D, Dejager S. Efficacy and tolerability of vildagliptin monotherapy in drug-naïve patients with type 2 diabetes. Diabetes Res Clin Pract. 2007;76(1):132-138.

24. Ahrén B, Landin-Olsson M, Jansson PA, Svensson M, Holmes D, Schweizer A. Inhibition of dipeptidyl peptidase-4 reduces glycemia, sustains insulin levels, and reduces glucagon levels in type 2 diabetes. J Clin Endocrinol Metab. 2004;89(5):2078-2084. 
25. Ahrén B, Schweizer A, Dejager S, et al. Vildagliptin enhances islet responsiveness to both hyper- and hypoglycemia in patients with type 2 diabetes. J Clin Endocrinol Metab. 2009;94(4):1236-1243.

26. Foley JE, Sreenan S. Efficacy and safety comparison between the DPP-4 inhibitor vildagliptin and the sulfonylurea gliclazide after two years of monotherapy in drug-naïve patients with type 2 diabetes. Horm Metab Res. 2009;41(12):905-909.

27. Pan C, Yang W, Barona JP, et al. Comparison of vildagliptin and acarbose monotherapy in patients with Type 2 diabetes: a 24-week, double-blind, randomized trial. Diabet Med. 2008;25(4):435-441.

28. Rosenstock J, Baron MA, Dejager S, Mills D, Schweizer A. Comparison of vildagliptin and rosiglitazone monotherapy in patients with type 2 diabetes: a 24-week, double-blind, randomized trial. Diabetes Care. 2007;30(2):217-223.

29. Schweizer A, Couturier A, Foley JE, Dejager S. Comparison between vildagliptin and metformin to sustain reductions in $\mathrm{HbA}(1 \mathrm{c})$ over 1 year in drug-naive patients with Type 2 diabetes. Diabet Med. 2007;24(9):955-961.

30. Pratley RE, Rosenstock J, Pi-Sunyer FX, et al. Management of type 2 diabetes in treatment-naive elderly patients: benefits and risks of vildagliptin monotherapy. Diabetes Care. 2007;30(12):3017-3022.

31. Kirpichnikov D, McFarlane SI, Sowers JR. Metformin: an update. Ann Intern Med. 2002;137(1):25-33.

32. Migoya EM, MJ, Larson PJ, Tanen MR, et al. Sitagliptin, a selective DPP-4 inhibitor, and metformin have complementary effects to increase. 43rd EASD Annual Meeting, Amsterdam; 2007.

33. Hinke SA, Kühn-Wache K, Hoffmann T, Pederson RA, McIntosh CH, Demuth HU. Metformin effects on dipeptidylpeptidase IV degradation of glucagon-like peptide-1. Biochem Biophys Res Commun. 2002;291(5):1302-1308.

34. Yasuda N, Inoue T, Nagakura T, et al. Enhanced secretion of glucagonlike peptide 1 by biguanide compounds. Biochem Biophys Res Commun. 2002;298(5):779-784.

35. D'Alessio DA, Denney AM, Hermiller LM, et al. Treatment with the dipeptidyl peptidase-4 inhibitor vildagliptin improves fasting islet-cell function in subjects with type 2 diabetes. $J$ Clin Endocrinol Metab. 2009;94(1):81-88.

36. Dunning BE, Ligueros-Saylan M, D'Alessio DA, et al. Differential effects of DPP-4 inhibition on incretin hormone levels in drug-naïve and metformin-treated patients with type 2 diabetes. Diabetologia. 2006;49(S1):S110.

37. Bosi E, Camisasca RP, Collober C, Rochotte E, Garber AJ. Effects of vildagliptin on glucose control over 24 weeks in patients with type 2 diabetes inadequately controlled with metformin. Diabetes Care. 2007;30(4):890-895.

38. Kim NHS, Sung YA, Ahn WC, et al. Efficacy and safety of add-on vildagliptin to metformin in comparison to uptitrating metformin therapy. Diabetes. 2012;61(S1):A297

39. Matthews DR, Dejager S, Ahren B, et al. Vildagliptin add-on to metformin produces similar efficacy and reduced hypoglycaemic risk compared with glimepiride, with no weight gain: results from a 2-year study. Diabetes Obes Metab. 2010;12(9):780-789.

40. Bolli G, Dotta F, Rochotte E, Cohen SE. Efficacy and tolerability of vildagliptin vs pioglitazone when added to metformin: a 24-week, randomized, double-blind study. Diabetes Obes Metab. 2008;10(1):82-90.

41. Bolli G, Dotta F, Colin L, Minic B, Goodman M. Comparison of vildagliptin and pioglitazone in patients with type 2 diabetes inadequately controlled with metformin. Diabetes Obes Metab. 2009;11(6):589-595.

42. Blonde L, Dagogo-Jack S, Banerji MA, et al. Comparison of vildagliptin and thiazolidinedione as add-on therapy in patients inadequately controlled with metformin: results of the GALIANT trial - a primary care, type 2 diabetes study. Diabetes Obes Metab. 2009;11(10):978-986.

43. Garber AJ, Schweizer A, Baron MA, Rochotte E, Dejager S. Vildagliptin in combination with pioglitazone improves glycaemic control in patients with type 2 diabetes failing thiazolidinedione monotherapy: a randomized, placebo-controlled study. Diabetes Obes Metab. 2007;9(2):166-174.
44. Garber AJ, Foley JE, Banerji MA, et al. Effects of vildagliptin on glucose control in patients with type 2 diabetes inadequately controlled with a sulphonylurea. Diabetes Obes Metab. 2008;10(11): 1047-1056.

45. Fonseca V, Baron M, Shao Q, Dejager S. Sustained efficacy and reduced hypoglycemia during one year of treatment with vildagliptin added to insulin in patients with type 2 diabetes mellitus. Horm Metab Res. 2008;40(6):427-430.

45. Fonseca V, Schweizer A, Albrecht D, Baron MA, Chang I, Dejager S. Addition of vildagliptin to insulin improves glycaemic control in type 2 diabetes. Diabetologia. 2007;50(6):1148-1155.

47. Lukashevich V, Kozlovski P, Foley J, et al. Vildagliptin combined with insulin reduces $\mathrm{HbA} 1 \mathrm{c}$ without increasing risk of hypoglycemia and weight gain in patients with type 2 diabetes mellitus. Proceedings from the 72nd ADA Scientific Sessions. Philadelphia, PA, USA; 2012.

48. Duttaroy A, Voelker F, Merriam K, et al. The DPP-4 inhibitor vildagliptin increases pancreatic beta cell mass in neonatal rats. Eur J Pharmacol. 2011;650(2-3):703-707.

49. Akarte AS, Srinivasan BP, Gandhi S. Vildagliptin selectively ameliorates GLP-1, GLUT4, SREBP-1c mRNA levels and stimulates $\beta$-Cell proliferation resulting in improved glucose homeostasis in rats with streptozotocin-induced diabetes. $J$ Diabetes Complications. 2012;26(4):266-274.

50. Sato K, Nakamura A, Shirakawa J, et al. Impact of the dipeptidyl peptidase-4 inhibitor vildagliptin on glucose tolerance and $\beta$-cell function and mass in insulin receptor substrate-2-knockout mice fed a high-fat diet. Endocrinology. 2012;153(3):1093-1102.

51. Hamamoto S, Kanda Y, Shimoda M, et al. Vildagliptin preserves the mass and function of pancreatic $\beta$ cells via the developmental regulation and suppression of oxidative and endoplasmic reticulum stress in a mouse model of diabetes. Diabetes Obes Metab. 2012; 15(2):153-163.

52. Balas B, Baig MR, Watson C, et al. The dipeptidyl peptidase IV inhibitor vildagliptin suppresses endogenous glucose production and enhances islet function after single-dose administration in type 2 diabetic patients. J Clin Endocrinol Metab. 2007;92(4):1249-1255.

53. Pratley RE, Schweizer A, Rosenstock J, et al. Robust improvements in fasting and prandial measures of beta-cell function with vildagliptin in drug-naïve patients: analysis of pooled vildagliptin monotherapy database. Diabetes Obes Metab. 2008;10(10):931-938.

54. Ahrén B, Pacini G, Foley JE, Schweizer A. Improved meal-related beta-cell function and insulin sensitivity by the dipeptidyl peptidase-IV inhibitor vildagliptin in metformin-treated patients with type 2 diabetes over 1 year. Diabetes Care. 2005;28(8):1936-1940.

55. Bosi E, Dotta F, Jia Y, Goodman M. Vildagliptin plus metformin combination therapy provides superior glycaemic control to individual monotherapy in treatment-naive patients with type 2 diabetes mellitus. Diabetes Obes Metab. 2009;11(5):506-515.

56. Utzschneider KM, Tong J, Montgomery B, et al. The dipeptidyl peptidase-4 inhibitor vildagliptin improves beta-cell function and insulin sensitivity in subjects with impaired fasting glucose. Diabetes Care. 2008;31(1):108-113.

57. Rosenstock J, Foley JE, Rendell M, et al. Effects of the dipeptidyl peptidase-IV inhibitor vildagliptin on incretin hormones, islet function, and postprandial glycemia in subjects with impaired glucose tolerance. Diabetes Care. 2008;31(1):30-35.

58. Avogaro A, Giorda C, Maggini M, et al; for Diabetes and Informatics Study Group, Association of Clinical Diabetologists, Istituto Superiore di Sanità. Incidence of coronary heart disease in type 2 diabetic men and women: impact of microvascular complications, treatment, and geographic location. Diabetes Care. 2007;30(5):1241-1247.

59. Gaede P, Lund-Andersen H, Parving HH, Pedersen O. Effect of a multifactorial intervention on mortality in type 2 diabetes. $N$ Engl J Med. 2008;358(6):580-591.

60. Monami M, Lamanna C, Desideri CM, Mannucci E. DPP-4 inhibitors and lipids: systematic review and meta-analysis. Adv Ther. 2012;29(1): $14-25$. 
61. Rosenstock J, Kim SW, Baron MA, et al. Efficacy and tolerability of initial combination therapy with vildagliptin and pioglitazone compared with component monotherapy in patients with type 2 diabetes. Diabetes Obes Metab. 2007;9(2):175-185.

62. Boschmann M, Engeli S, Dobberstein K, et al. Dipeptidyl-peptidase-IV inhibition augments postprandial lipid mobilization and oxidation in type 2 diabetic patients. J Clin Endocrinol Metab. 2009;94(3):846-852.

63. Ahrén B, Schweizer A, Dejager S, Villhauer EB, Dunning BE, Foley JE. Mechanisms of action of the dipeptidyl peptidase-4 inhibitor vildagliptin in humans. Diabetes Obes Metab. 2011;13(9):775-783.

64. Terasaki M, Nagashima M, Watanabe T, et al. Effects of PKF275055, a dipeptidyl peptidase-4 inhibitor, on the development of atherosclerotic lesions in apolipoprotein E-null mice. Metabolism. 2012;61(7):974-977.

65. Chinda K, Palee S, Surinkaew S, Phornphutkul M, Chattipakorn S, Chattipakorn N. Cardioprotective effect of dipeptidyl peptidase-4 inhibitor during ischemia-reperfusion injury. Int J Cardiol. Epub January 26, 2012.

66. Apaijai N, Pintana H, Chattipakorn SC, Chattipakorn N. Cardioprotective effects of metformin and vildagliptin in adult rats with insulin resistance induced by a high-fat diet. Endocrinology. 2012;153(8):3878-3885.

67. Matsui T, Nishino Y, Takeuchi M, Yamagishi S. Vildagliptin blocks vascular injury in thoracic aorta of diabetic rats by suppressing advanced glycation end product-receptor axis. Pharmacol Res. 2011;63(5) 383-388.

68. Pratley RE, Jauffret-Kamel S, Galbreath E, Holmes D. Twelve-week monotherapy with the DPP-4 inhibitor vildagliptin improves glycemic control in subjects with type 2 diabetes. Horm Metab Res. 2006;38(6):423-428.

69. Kikuchi M, Abe N, Kato M, Terao S, Mimori N, Tachibana H. Vildagliptin dose-dependently improves glycemic control in Japanese patients with type 2 diabetes mellitus. Diabetes Res Clin Pract. 2009;83(2):233-240.

70. Monami M, Cremasco F, Lamanna C, Marchionni N, Mannucci E. Predictors of response to dipeptidyl peptidase-4 inhibitors: evidence from randomized clinical trials. Diabetes Metab Res Rev. 2011;27(4):362-372.

71. Göke B, Hershon K, Kerr D, et al. Efficacy and safety of vildagliptin monotherapy during 2-year treatment of drug-naïve patients with type 2 diabetes: comparison with metformin. Horm Metab Res. 2008;40(12):892-895.

72. Iwamoto Y, Kashiwagi A, Yamada N, et al. Efficacy and safety of vildagliptin and voglibose in Japanese patients with type 2 diabetes: a 12-week, randomized, double-blind, active-controlled study. Diabetes Obes Metab. 2010;12(8):700-708.

73. Cai L, Cai Y, Lu ZJ, Zhang Y, Liu P. The efficacy and safety of vildagliptin in patients with type 2 diabetes: a meta-analysis of randomized clinical trials. J Clin Pharm Ther. 2012;37(4):386-398.

74. Berlie HD, Garwood CL. Diabetes medications related to an increased risk of falls and fall-related morbidity in the elderly. Ann Pharmacother. 2010;44(4):712-717.

75. Gerstein HC, Miller ME, Genuth S, et al; for ACCORD Study Group. Long-term effects of intensive glucose lowering on cardiovascular outcomes. N Engl J Med. 2011;364(9):818-828.

76. Gooßen K, Gräber S. Longer term safety of dipeptidyl peptidase-4 inhibitors in patients with type 2 diabetes mellitus: systematic review and meta-analysis. Diabetes, Obesity and Metabolism. 2012;14(12): 1061-1072.

Therapeutics and Clinical Risk Management

\section{Publish your work in this journal}

Therapeutics and Clinical Risk Management is an international, peerreviewed journal of clinical therapeutics and risk management, focusing on concise rapid reporting of clinical studies in all therapeutic areas, outcomes, safety, and programs for the effective, safe, and sustained use of medicines. This journal is indexed on PubMed Central, CAS,
77. Bryan J, Crane A, Vila-Carriles WH, Babenko AP, Aguilar-Bryan L. Insulin secretagogues, sulfonylurea receptors and K(ATP) channels. Curr Pharm Des. 2005;11(21):2699-2716.

78. Ward WK, Beard JC, Halter JB, Pfeifer MA, Porte D Jr. Pathophysiology of insulin secretion in non-insulin-dependent diabetes mellitus. Diabetes Care. 1984;7(5):491-502.

79. Tan MH, Baksi A, Krahulec B, et al; for GLAL Study Group. Comparison of pioglitazone and gliclazide in sustaining glycemic control over 2 years in patients with type 2 diabetes. Diabetes Care. 2005;28(3):544-550.

80. Kahn SE, Haffner SM, Heise MA, et al; for ADOPT Study Group. Glycemic durability of rosiglitazone, metformin, or glyburide monotherapy. N Engl J Med. 2006;355(23):2427-2443.

81. Christensen M, Vedtofte L, Holst JJ, Vilsbøll T, Knop FK. Glucosedependent insulinotropic polypeptide: a bifunctional glucose-dependent regulator of glucagon and insulin secretion in humans. Diabetes. 2011;60(12):3103-3109.

82. Marfella R, Barbieri M, Grella R, Rizzo MR, Nicoletti GF, Paolisso G. Effects of vildagliptin twice daily vs sitagliptin once daily on 24-hour acute glucose fluctuations. J Diabetes Complications. 2010; 24(2):79-83.

83. Nathan DM, Buse JB, Davidson MB, et al; for American Diabetes Association, European Association for Study of Diabetes. Medical management of hyperglycemia in type 2 diabetes: a consensus algorithm for the initiation and adjustment of therapy: a consensus statement of the American Diabetes Association and the European Association for the Study of Diabetes. Diabetes Care. 2009;32(1):193-203.

84. Becker A, Bos G, de Vegt F, et al. Cardiovascular events in type 2 diabetes: comparison with nondiabetic individuals without and with prior cardiovascular disease. 10-year follow-up of the Hoorn Study. Eur Heart J. 2003;24(15):1406-1413.

85. Lee CD, Folsom AR, Pankow JS, Brancati FL; for Atherosclerosis Risk in Communities (ARIC) Study Investigators. Cardiovascular events in diabetic and nondiabetic adults with or without history of myocardial infarction. Circulation. 2004;109(7):855-860.

86. Nissen SE, Wolski K. Effect of rosiglitazone on the risk of myocardial infarction and death from cardiovascular causes. $N$ Engl J Med. 2007;356(24):2457-2471.

87. Kendall DM, Rubin CJ, Mohideen P, et al. Improvement of glycemic control, triglycerides, and HDL cholesterol levels with muraglitazar, a dual (alpha/gamma) peroxisome proliferator-activated receptor activator, in patients with type 2 diabetes inadequately controlled with metformin monotherapy: A double-blind, randomized, pioglitazone-comparative study. Diabetes Care. 2006;29(5):1016-1023.

88. Schweizer A, Dejager S, Foley JE, Couturier A, Ligueros-Saylan M, Kothny W. Assessing the cardio-cerebrovascular safety of vildagliptin: meta-analysis of adjudicated events from a large Phase III type 2 diabetes population. Diabetes Obes Metab. 2010;12(6):485-494.

89. Lukashevich V, Schweizer A, Shao Q, Groop PH, Kothny W. Safety and efficacy of vildagliptin versus placebo in patients with type 2 diabetes and moderate or severe renal impairment: a prospective 24-week randomized placebo-controlled trial. Diabetes Obes Metab. 2011;13(10):947-951.

90. Schillinger D, Grumbach K, Piette J, et al. Association of health literacy with diabetes outcomes. JAMA. 2002;288(4):475-482. 